\title{
Short Communication: Tissue Distribution of Leptin and Leptin Receptor mRNA in the Bovine
}

\author{
P. K. Chelikani, D. R. Glimm, and J. J. Kennelly \\ Department of Agricultural, Food and Nutritional Science, \\ University of Alberta, Edmonton, Canada T6G 2P5
}

\begin{abstract}
Detection of leptin and leptin receptor mRNA in various tissues is crucial to an understanding of leptin physiology in dairy cattle. We report here evidence of leptin receptor gene expression in central and peripheral tissues of the bovine by reverse transcription and polymerase chain reaction analysis. Leptin mRNA was detectable in mammary parenchyma and in adipose tissue with similar transcript abundance among the subcutaneous, pericardial, perirenal, and mesenteric adipose depots. The mRNA for the long-form of the leptin receptor, Ob-Rb, was detectable in all four adipose depots, mammary parenchyma, semintendinosus muscle, liver, adrenal cortex, spleen, kidney, testis, mesenteric lymph node, lung, aorta, abomasum, duodenum, jejunum, ileum, hypothalamus, pituitary, brain stem, cerebral cortex, cerebellar cortex, pons, and pineal gland. The mRNA for the short form of the leptin receptor, Ob$\mathrm{Ra}$, was detectable in the liver, adrenal cortex, spleen, pituitary, and brain stem, but not in the other tissues surveyed. The wide spectrum of tissues expressing the leptin receptor gene reveals that leptin may have multiple physiological functions in the bovine.
\end{abstract}

(Key words: cattle, leptin, leptin receptor)

Abbreviation key: GAPDH = glyceraldehyde 3-phosphate dehydrogenase, $\mathbf{R T}=$ reverse transcription.

Leptin, a hormone secreted primarily from adipose tissue, has been reported to play a role in various physiological functions such as energy homeostasis, reproduction, cardiovascular, renal, immune and stress responses, and bone formation (Fruhbeck, 2001). The hormone acts through five receptor isoforms that have identical extracellular and transmembrane domains but differ in their intracellular domain. Among these

Received November 11, 2002.

Accepted February 28, 2003.

Corresponding author: J. J. Kennelly; e-mail: John.Kennelly@ ualberta.ca. isoforms, only the long form of the receptor (Ob-Rb), with the complete intracellular domain, is fully functional and is responsible for most of the physiological effects of leptin (Tartaglia, 1997). The short form of the receptor (Ob-Ra), with a truncated intracellular domain, has limited signal transduction capability (Bjorbaeck et al., 1997), but could be involved in leptin transport (Hileman et al., 2002) and catecholamine synthesis (Yanagihara et al., 2000). Although the expression of functional leptin receptors is highest in the central nervous system, the widespread distribution of the receptors in various peripheral tissues in monogastric species is evidence of multiple peripheral effects of leptin (Fruhbeck, 2001).

As a first step towards understanding the central and peripheral effects of leptin in cattle, it is necessary to demonstrate the gene expression of leptin and its cognate receptors in various tissues. The key objective of this study was to determine the presence of mRNA corresponding to leptin and its long-form $(\mathrm{Ob}-\mathrm{Rb})$ and short-form receptors (Ob-Ra) in various central and peripheral tissues in male Holstein calves. We also examined by semiquantitative reverse transcription (RT)PCR the relative expression of the leptin gene in four adipose depots.

The experiment was conducted at the Metabolic Research Centre, University of Alberta, with all animal procedures approved by the Faculty Animal Policy and Welfare Committee. Three male Holstein calves (196.7 $\pm 15.62 \mathrm{~kg} \mathrm{BW}$ ) were used in this study. Within $45 \mathrm{~min}$ of slaughter 27 tissues were collected: subcutaneous fat, pericardial fat, perirenal fat, mesenteric fat, masseter muscle, semintendinosus muscle, endocardium, liver, adrenal cortex, spleen, kidney, testis, mesenteric lymph node, lung, aorta, rumen, abomasum, duodenum, jejunum, ileum, hypothalamus, pituitary, brain stem, cerebral cortex, cerebellar cortex, pons, and pineal gland. Samples were snap-frozen in liquid nitrogen and subsequently stored at $-80^{\circ} \mathrm{C}$.

All reagents used were from Invitrogen Life Technologies (Invitrogen Canada Inc., Burlington, ON, Canada). Total RNA was isolated from pulverized tissues with TRIzol reagent and quantified by absorbance at $260 \mathrm{~nm}$ in a spectophotometer; only samples with a 260 
Table 1. Primer pairs for reverse transcriptase-PCR amplification of each target gene, annealing temperature (AT), number of cycles of amplification, and length (base pairs, bp) of PCR products.

\begin{tabular}{lllll}
\hline Target & Primers $^{1}$ & AT & Cycles & Length (bp) \\
\hline Leptin & F: 5'-GTGCCCATCCGCAAGGTCC-3' & $60^{\circ} \mathrm{C}$ & 40 & 441 \\
& R: 5'-TCAGCACCCGGGACTGAGG-3' & & & \\
Ob-Rb $^{2}$ & F: 5'-GTGCCAGCAACTACAGATGCTCTAC-3' & $65^{\circ} \mathrm{C}$ & 45 & 380 \\
& R: 5'-AGTTCATCCAGGCCTTCTGAGAACG-3' & & & \\
Ob-Ra $^{3}$ & F: 5'-TTGAGAAGTACCAGTTCAGTC-3' & $60^{\circ} \mathrm{C}$ & 45 & 281 \\
& R: 5'-CAAAGAATGTCCGTTCTCTTC-3' & & & \\
GAPDH $^{4}$ & F: 5'-CTGGCAAAGTGGACATTGTCGCC-3' & $65^{\circ} \mathrm{C}$ & 35 & 572 \\
& R: 5'-CTTGGCAGCGCCGGTAGAAGC-3' & & & \\
\hline
\end{tabular}

${ }^{1} \mathrm{~F}, \mathrm{R}$ : Forward and Reverse primers. Bovine-specific primer sequences for the ${ }^{2}$ long-form of the leptin receptor $(\mathrm{Ob}-\mathrm{Rb})$ were from Parhami et al. (2001) and for the ${ }^{3}$ short-form of the leptin receptor were from Yanagihara et al. (2000). ${ }^{4}$ Glyceraldehyde 3-phosphate dehydrogenase (GAPDH).

$\mathrm{nm}: 280 \mathrm{~nm}$ ratio $>1.9$ were used for further analysis. The RT-PCR were carried out in a DNA thermocycler (PCR System 2400, Perkin Elmer, Mississauga, ON, Canada). First-strand complementary DNA (cDNA) was synthesized from $2 \mu \mathrm{g}$ of total RNA in a $20-\mu \mathrm{l}$ reaction volume with a final concentration of $25 \mathrm{ng}$ of Oligo $(\mathrm{dT})_{12-18}$ primer, $0.5 \mathrm{~m} M$ dNTP mix, $4 \mu \mathrm{l}$ of $5 \times$ firststrand buffer, $0.01 M$ dithiothreitol, $2 \mathrm{U}$ of RNaseOUT, and $1 \mathrm{U}$ of Supersript II RNase $\mathrm{H}^{-}$reverse transcriptase. The reaction was carried out at $42^{\circ} \mathrm{C}$ for 50 min, and $70^{\circ} \mathrm{C}$ for $15 \mathrm{~min}$. Aliquots of $2 \mu \mathrm{l}$ of the firststrand $\mathrm{cDNA}$ reaction were amplified in a $50-\mu \mathrm{l}$ reaction volume containing a final concentration of $5 \mu \mathrm{l}$ of $10 \times$ PCR buffer, $1.5 \mathrm{mM} \mathrm{MgCl} 2,0.2 \mathrm{~m} M$ dNTP mix, $2 \mathrm{U}$ of recombinant Taq DNA polymerase, and $0.4 \mu M$ of each primer. Following an initial denaturation at $94^{\circ} \mathrm{C}$ for $3 \mathrm{~min}$, PCR was performed for a variable number of cycles (Table 1) of denaturation at $94^{\circ} \mathrm{C}$ for $1 \mathrm{~min}$, specific annealing temperature (Table 1) for $1 \mathrm{~min}$, extension at $72^{\circ} \mathrm{C}$ for $2 \mathrm{~min}$, and a final extension of $72^{\circ} \mathrm{C}$ for $10 \mathrm{~min}$ in the last cycle. The PCR products were electrophoresed on a $2 \%$ agarose gel in Tris-borate EDTA buffer, stained with ethidium bromide, the images captured with a Gel Doc 1000 system, and the PCR product density analyzed with Molecular Analyst software (Bio-Rad Laboratories, Mississauga, ON, Canada).

For each tissue and target gene, negative controls without reverse transcriptase yielded no amplification, confirming that genomic DNA was not amplified (data not shown). Further, the primer pairs for leptin were designed to be located on different exons as a precaution against amplification of genomic DNA. The housekeeping gene glyceraldehyde 3-phosphate dehydrogenase (GAPDH) was used as an internal control. The abundance of leptin mRNA in the four adipose depots was compared by a semiquantitative RT-PCR method. In a preliminary study, cDNA samples, in duplicate, were amplified from 12 to 34 cycles for GAPDH, and from
20 to 38 cycles for leptin. Based on these amplification plots (Figure 1), the optical density of leptin $\left(r^{2}=0.97\right)$ and GAPDH $\left(r^{2}=0.98\right)$ PCR products were each modeled as a function of number of amplification cycles by a cubic regression equation $(P<0.001)$ using PRISM (GraphPad Software Inc., San Diego, CA). To ensure that PCR was conducted in the linear range of amplification, cDNA samples were amplified for 28 cycles for leptin and 25 cycles for GAPDH. The PCR products were quantified as detailed above, and the ratio of leptin to GAPDH in duplicate RNA samples from the four adipose depots was analyzed by ANOVA using the MIXED procedure of SAS (1999).

The distribution of leptin and leptin receptor mRNA in various tissues is depicted in Figure 2. Leptin mRNA was detectable only in adipose tissue with no difference $(P>0.10)$ in transcript abundance among the four adipose depots (Figure 1). At the time that this manuscript was submitted, the paper by Silva et al. (2002) on tissue distribution of leptin receptor mRNA in bovine tissues had not been published. In addition to confirming the expression of Ob-Ra mRNA in pituitary, liver, and spleen, reported by Silva et al. (2002), we were also able to detect Ob-Ra transcripts in the adrenal cortex and brain stem. The mRNA for the long form of the leptin receptor, Ob-Rb, was detectable in all four adipose depots, semintendinosus muscle, liver, spleen, testis, hypothalamus, pituitary, and lung, which is in agreement with the data in bovine (Silva et al., 2002; Ren et al., 2002) and swine (Lin et al., 2000). Further, Ob-Rb mRNA was also detectable in the adrenal cortex, kidney, mesenteric lymph node, aorta, abomasum, duodenum, jejunum, ileum, brain stem, cerebral cortex, cerebellar cortex, pons, and pineal gland, but was undetectable in endocardium and massetor muscle. In accord with studies in sheep (Laud et al., 1999; Bonnet et al., 2002) and cattle (Silva et al., 2002; Smith and Sheffield, 2002) transcripts for both leptin and Ob-Rb 
A

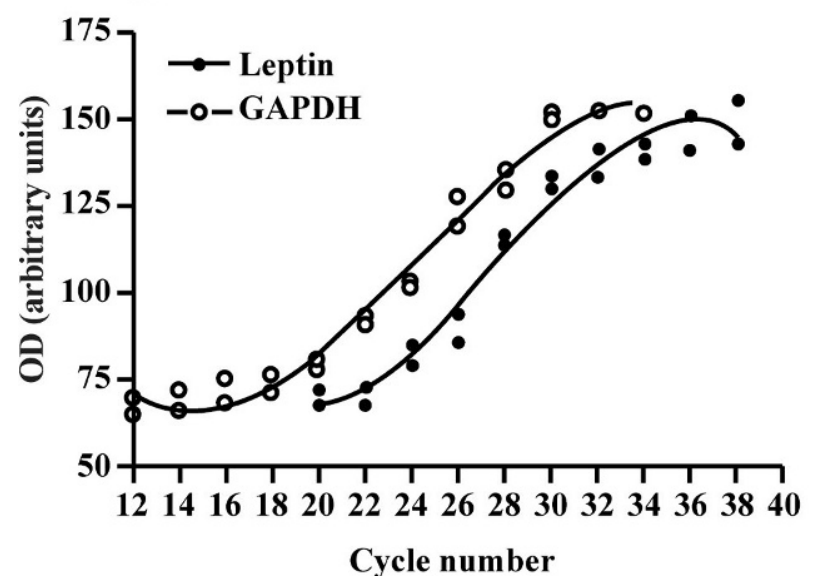

B

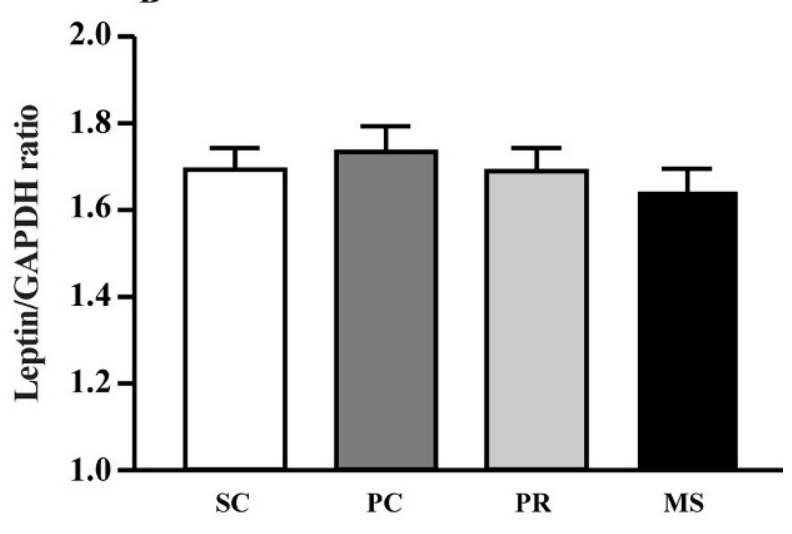

Figure 1. Semiquantitative reverse transcription-PCR for determining relative abundance of leptin mRNA in adipose depots of male Holstein calves. A cubic regression equation $(P<0.001)$ was used to model the optical density $(\mathrm{OD})$ of leptin $\left(\mathrm{r}^{2}=0.97\right)$ and glyceraldehyde 3-phosphate dehydrogenase (GAPDH; $\mathrm{r}^{2}=0.98$ ) PCR products as a function of number of amplification cycles (A). The ratio of mRNA abundance of leptin to GAPDH in subcutaneous (SC), pericardial (PC), perirenal (PR), and mesenteric (MS) adipose depots (B).

were detectable in mammary parenchyma from a multiparous Holstein cow (data not shown).

Recent molecular evidence indicates the presence of Ob-Rb transcripts in bovine aortic cells (Parhami et al., 2001), and Ob-Ra transcripts in bovine adrenal medullary cells (Yanagihara et al., 2000). That these receptors are functional was supported by the ability of leptin to induce calcification of aortic cells through $\mathrm{Ob}-\mathrm{Rb}$, and to stimulate catecholamine synthesis in adrenal medullary cells through Ob-Ra. As the Ob-Rb and Ob-Ra primer sequences that we have used were from the above two reports we speculate that the expression of $\mathrm{Ob}-\mathrm{Rb}$ and $\mathrm{Ob}-\mathrm{Ra}$ transcripts in tissues that we have surveyed may have tissue-specific functional significance. The fact that most but not all tissues expressed transcripts for Ob-Rb or Ob-Ra indicates that leptin must play a role in several physiological functions. Consistent with a central role for leptin in the regulation of energy balance and reproduction (Fruhbeck, 2001), the abundance of the Ob-Rb transcript seems to be much higher in the hypothalamus and pituitary compared to other peripheral tissues. The presence of ObRb mRNA in testis is suggestive of a direct role for leptin in testicular function. That leptin might be involved in lipid metabolism is suggested from the presence of Ob$\mathrm{Rb}$ transcripts in adipose tissue, semintendinosus mus-

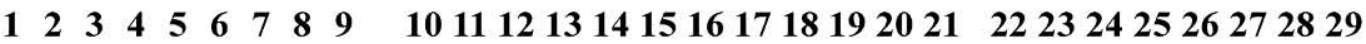

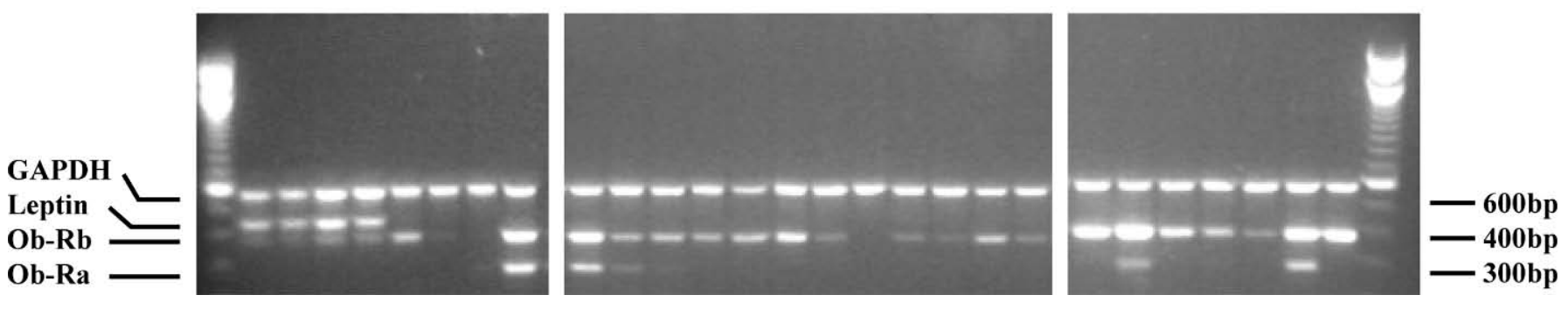

Figure 2. Detection of mRNA corresponding to leptin, the long-form (Ob-Rb) and short-form (Ob-Ra) of the leptin receptor, and glyceraldehyde 3-phosphate dehydrogenase (GAPDH) in various peripheral and central tissues of a typical male Holstein calf by reverse transcription polymerase chain reaction. Lanes (Ln) 1 and 29, 100-bp DNA ladders; Ln 2, subcutaneous fat; Ln 3, pericardial fat; Ln 4, perirenal fat; Ln 5, mesenteric fat; Ln 6, semintendinosus muscle; Ln 7, masseter muscle; Ln 8, endocardium; Ln 9, liver; Ln 10, adrenal cortex; Ln 11, spleen; Ln 12, kidney; Ln 13, testis; Ln 14, mesenteric lymph node; Ln 15, lung; Ln 16, aorta; Ln 17, rumen; Ln 18, abomasum; Ln 19, duodenum; Ln 20, jejunum; Ln 21, ileum; Ln 22, hypothalamus; Ln 23, pituitary; Ln 24, pons; Ln 25, cerebral cortex; Ln 26, cerebellar cortex; Ln 27, brain-stem; and Ln 28, pineal gland. 
cle, and liver. The detection of Ob-Rb message in spleen and mesenteric lymph node suggests an involvement of leptin in immune function, and presence of $\mathrm{Ob}-\mathrm{Rb}$ transcript in the adrenal cortex may indicate a role for leptin in stress response and acid-base balance. Leptin may also be involved in digestion, respiration, and renal and cardiovascular functions as evidenced by the presence of $\mathrm{Ob}-\mathrm{Rb} \mathrm{mRNA}$ in various regions of the gastrointestinal tract, lung, kidney, and aorta, respectively. Although the functional significance of $\mathrm{Ob}-\mathrm{Ra}$ in the liver remains to be determined, the presence of Ob-Ra mRNA in the adrenal cortex may implicate leptin in adrenal function. The Ob-Ra transcript in the brain stem may be involved in leptin transport as has been suggested for rodents (Hileman et al., 2002).

In conclusion, our data on differential tissue expression of the leptin receptor gene provide evidence for potential involvement of leptin in multiple physiological functions in cattle. Quantification of transcript abundance of leptin receptors in various tissues in response to nutritional and (or) hormonal manipulations, in concert with immunocytochemical localization of leptin receptors in different cell types, should prove useful in delineating the functional significance of leptin receptors in various tissues in cattle.

\section{ACKNOWLEDGMENTS}

Financial assistance for this research was provided by the Alberta Agricultural Research Institute, Natural Sciences and Engineering Research Council of Canada, and Alberta Milk. We appreciate the help of the technical staff at the Dairy Research and Technology Centre and the Metabolic Research Unit, and fellow researchers, in sample collection.

\section{REFERENCES}

Bonnet, M., I. Gourdou, C. Leroux, Y. Chilliard, and J. Djiane. 2002. Leptin expression in the ovine mammary gland: putative sequential involvement of adipose, epithelial, and myoepithelial cells during pregnancy and lactation. J. Anim. Sci. 80:723-728.

Fruhbeck, G. A heliocentric view of leptin. 2001. Proc. Nutr. Soc. 60:301-318.

Hileman, S. M., D. D. Pierroz, H. Masuzaki, C. Bjorbaek, K. ElHaschimi, W. A. Banks, and J. S. Flier. 2002. Characterizaton of short isoforms of the leptin receptor in rat cerebral microvessels and of brain uptake of leptin in mouse models of obesity. Endocrinology 143:775-783.

Laud, K., I. Gourdou, L. Belair, D. H. Keisler, and J. Djiane. 1999. Detection and regulation of leptin receptor mRNA in ovine mammary epithelial cells during pregnancy and lactation. FEBS Lett. 463:194-198.

Lin, J., C. R. Barb, R. L. Matteri, R. R. Kraeling, X. Chen, R. J. Meinersmann, and G. B. Rampacek. 2000. Long form leptin receptor mRNA expression in the brain, pituitary, and other tissues in the pig. Domest. Anim. Endocrinol. 19:53-61.

Parhami, F., Y. Tintut, A. Ballard, A. M. Fogelman, and L. L Demer. 2001. Leptin enhances the calcification of vascular cells: Artery wall as a target of leptin. Circ. Res. 88:954-960.

SAS User's Guide: Statistics, Version 6.12. 1999. SAS Inst., Inc., Cary, NC.

Ren, M. Q., J. Wegner, O. Bellmann, G. A. Brockmann, F. Schneider, F. Teuscher, and K. Ender. 2002. Comparing mRNA levels of genes encoding leptin, leptin receptor, and lipoprotein lipase between dairy and beef cattle. Domest. Anim. Endocrinol. 23:371-381.

Silva, L. F. P., M. J. VandeHaar, M. S. Weber Nielsen, and G. W. Smith. 2002. Evidence for a local effect of leptin in bovine mammary gland. J. Dairy Sci. 85:3277-3266.

Smith, J. L., and L. G. Sheffield. 2002. Production and regulation of leptin in bovine mammary epithelial cells. Domest. Anim. Endocrinol. 22:145-154.

Tartaglia, L. A. The leptin receptor. 1997. J. Biol. Chem. 272:6093-6096.

Yanagihara, N., K. Utsunomiya, T. B. Cheah, H. Hirano, K. Kajiwara, K. Hara, E. Nakamura, Y. Toyohira, Y. Uezono, S. Ueno, and F. Izumi. 2000. Characterization and functional role of leptin receptor in bovine adrenal medullary cells. Biochem. Pharmacol. 59:1141-1145. 